\title{
CLINICAL AND EPIDEMIOLOGICAL PROFILE OF BREATH HOLDING SPELLS (BHS)- AN ANALYSIS OF 115 CASES
}

\author{
R. Bhavanishankar 1 , P. Ramu2 ${ }^{2}$ Nuka Chaitanya ${ }^{3}$
}

${ }^{1}$ Associate Professor, Department of Paediatrics, Sri Venkateswara Medical College, Tirupati.

${ }^{2}$ Associate Professor, Department of Paediatrics, Government Medical College, Ananthapuramu.

${ }^{3}$ Senior Resident, Department of Paediatrics, Andhra Medical College, Visakhapatnam.

\begin{tabular}{l}
\hline ABSTRACT \\
BACKGROUND \\
Breath holding spells are common in non-epileptic, repetitive, paroxysmal events in young infants and children often considered as \\
seizure mimics/ confused with seizure disorder can be a frightening experience for parents and demands a good history of the \\
sequence of events, because the diagnosis is made clinically. \\
Aims and Objectives- To study the disease spectrum of Breath holding spells in infants and children in terms of clinical and \\
epidemiological profile (i.e. age, sex, family history, parental consanguinity, triggering factors, associated comorbidities such as \\
anaemia etc.).
\end{tabular}

\section{MATERIALS AND METHODS}

This case series study was conducted in our Child health clinics. A total of 125 children below 6 years with Breath holding spells were enrolled between May 2012 and April 2017, out of which 10 children were excluded from the study due to various causes. Remaining 115 children diagnosed as Breath holding spells by typical history, clinical examination and after ruling out other causes which mimic Breath holding spells are included in the study.

\section{RESULTS}

In the present study, a total of 115 children aged between 6 months and below 6 years were diagnosed as having Breath holding spells. In 73 (63.41\%) cases Breath holding spells began during the first 24 months of age. Most common triggering factor being anger (45.2\%) and pain (41.7\%). A positive family history was found in $27 \%$ and parental consanguinity was found in $30.43 \%$ of cases. The spells were cyanotic in $62.6 \%$ and $76.52 \%$ were anaemic.

\section{CONCLUSION}

The result of this study suggests a new data regarding the natural history of Breath holding spells and is important for identifying interventional strategies and parental counselling and could serve as baseline data for future approaches on this paediatric clinical entity.

\section{KEYWORDS}

Breath Holding Spells, Cyanotic, Pallid, Anaemia.

HOW TO CITE THIS ARTICLE: Bhavanishankar R, Ramu P, Chaitanya N. Clinical and epidemiological profile of breath holding spells (BHS)- an analysis of 115 cases. J. Evolution Med. Dent. Sci. 2018;7(04):534-539, DOI: 10.14260/jemds/2018/119

\section{BACKGROUND}

Breath holding spells are common in non-epileptic, repetitive, reflexive events described under "behavioural disorders" of children and are initiated by provocative events that cause anger, frustration or pain causing the child to cry. The term Breath holding spells is actually a misnomer, as these are not self-induced but results from immaturity of autonomic system and occurs in two different forms. The first type is pallid Breath holding spells. The second type is the cyanotic or blue Breath holding spells. Episodes usually start with a cry (often in the case of pallid type, a silent cry with marked pallor) and progress to apnoea and cyanosis. Some authors have described third variety as mixed Breath holding spells,

'Financial or Other Competing Interest': None.

Submission 19-11-2017, Peer Review 06-01-2018,

Acceptance 13-01-2018, Published 22-01-2018.

Corresponding Author:

Dr. P. Ramu,

Raja Sagi Residency,

$F_{3^{\prime}}$ D. No. 14-1-122/13,

Nowroji Road, Maharanipeta

Visakhapatnam-530002, A. P.

E-mail: drpramu73@gmail.com

DOI: $10.14260 /$ jemds $/ 2018 / 119$ wherein both pallor and cyanosis occur in same child during the spell. Spells usually begin between 6 and 18 months of age. Breath holding spells are rare below 6 months, peak by 2 years and abate by 5 years. Syncope, tonic posturing and reflex anoxic seizure may follow the more severe episode, particularly in Breath holding spells of pallid type. Injury, anger and frustration, particularly with surprise are common triggers. The prevalence of Breath holding spells described variously between $5 \%$ and $15 \% .^{1}$ Many authors have proposed the prevalence of an underlying dysfunctional autonomic nervous system in children with Breath holding spells. Other reports suggested an association between anaemia and Breath holding spells. Breath holding spells usually mimic or are confused with seizure disorder and can be a frightening experience for parents. Since the diagnosis is made clinically it demands a good history of sequence of events, lack of incontinence and postictal phase helps to make an accurate diagnosis. Education and reassurance of the parents usually all that is needed as these episodes are as a rule self-limited and are outgrown within a few years or by school age. However, treatment of coexisting anaemia or iron deficiency is needed if it is present as the spells are made worse by iron deficiency anaemia.1,2,3,4 Hence, we analysed 
the clinical and epidemiological profile of children with Breath holding spells in our study.

\section{MATERIALS AND METHODS}

This case series study was conducted in our "Child health clinics." A total of 125 children below 6 years with Breath holding spells were enrolled between May 2012 and April 2017, out of which 10 children were excluded from the study because these children had other associated problems (like one child had Atrial septal defect, two children had Ventricular septal defect, three children had history of febrile convulsions and four children were lost for follow-up in due course). All children diagnosed as Breath holding spells by typical history, clinical examination and after ruling out other causes which mimic Breath holding spells are included in the study. A structured interview was undertaken at the time of initial consultation to confirm Breath holding spells and its type, sex and age at initial spells, laboratory tests, (CBC, EEG, ECG, 2D Echo and neuroimaging studies etc.) were done depending upon the demand of clinical situation to exclude other causes and comorbidities such as epilepsy/ seizures, congenital cyanotic heart diseases, prolonged QT syndrome, Chiari crisis and Brain stem lesions.

\section{RESULTS}

In the present study, a total of 115 children were diagnosed as Breath holding spells between 6 months and 60 months. In our study, Breath holding spells are observed more frequently in boys than in girls (58.3\% vs. $41.7 \%)$. Hence, $\mathrm{M} / \mathrm{F}$ ratio is 1.4: 1 (Table 1) in agreement with Ashrafi et al study (1999) of M/ F ratio of 1.15: 1. A positive family history was found in $27 \%$ (31 out of 115 ) and parental consanguinity was found in $30.43 \%$ (35 out of 115) of cases. The spells were cyanotic in $62.6 \%$ ( 72 out of 115 ) and pallid in $30.4 \%$ (35 out of 115). In our study, none of the children had mixed form of Breath holding spells. Most common triggering factors in the present study being anger $45.2 \%$ (52 out of 115 ) and pain $41.7 \%$ (48 out of 115), in agreement with the previous studies (Table 1). In the present study, about $76.52 \%$ (88 children out of 115) had anaemia (Table 2). In 73 (63.41\%) cases, Breath holding spells began during the first 24 months of age (Table 3). In our study family history of Breath holding spells were found in $27 \%$ of children, whereas in Daoud study (1997) 47.5\% and in Ashrafi MR study (1999) 51.2\% (Table 4). In our study about $30.43 \%$ (35 out of 115 ) cases have positive history of parental consanguinity in agreement with Ashrafi MR study (Table 5).

\begin{tabular}{|c|c|c|c|c|}
\hline \multicolumn{3}{|c|}{ Parameters } & Number $(n=115)$ & $(\%)$ \\
\hline \multirow{2}{*}{ Sex } & & Boys & 67 & 58.3 \\
\hline & & Girls & 48 & 41.7 \\
\hline \multirow{2}{*}{ Family History } & & Yes & 31 & 27 \\
\hline & & No & 84 & 73 \\
\hline \multirow{2}{*}{ Parental Consanguinity } & & Yes & 35 & 30.4 \\
\hline & & No & 80 & 69.6 \\
\hline \multirow{2}{*}{ Type of Attack } & & Cyanotic & 76 & 66.1 \\
\hline & & Pallid & 39 & 33.9 \\
\hline \multirow{4}{*}{ Triggering Factor } & & Anger & 52 & 45.2 \\
\hline & Pain & Injection (vaccination) & 48 & 41.7 \\
\hline & & Frustration & 11 & 9.5 \\
\hline & & Fear & 4 & 3.4 \\
\hline
\end{tabular}

\begin{tabular}{|c|c|}
\hline Haematological Classification according to Hb\% and RBC Indices & Number \\
\hline Number of BHS children with anaemia & 88 \\
\hline Number of BHS children with normal Hb\% and RBC indices & 27 \\
\hline Table 2. Haematological Classification according to Hb\% and RBC Indices in the Present Study (n= 115) \\
\hline
\end{tabular}

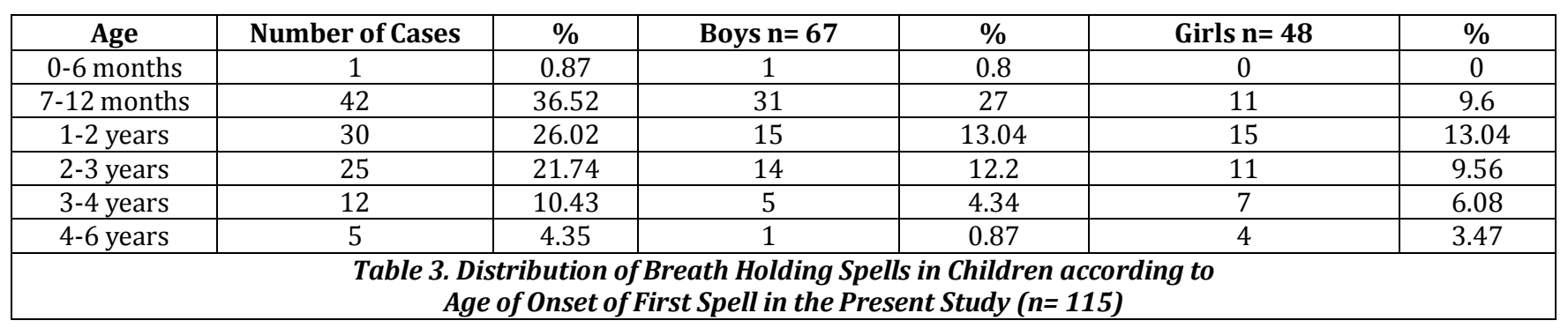

\begin{tabular}{|c|c|}
\hline Study & $\%$ of Cases with Positive Family History of Breath Holding Spells \\
\hline Daoud Study (1997) & $47.5 \%$ \\
\hline Ashrafi MR Study (1999) & $51.2 \%$ \\
\hline Present Study & $27 \%$ \\
\hline Table 4. Comparison among Different Studies regarding Percentage of \\
Cases having Positive Family History of Breath Holding Spells \\
\hline
\end{tabular}




\begin{tabular}{|c|c|}
\hline Study & $\begin{array}{c}\text { \% of Cases with Positive History of Parental Consanguinity among } \\
\text { Children with Breath Holding Spells }\end{array}$ \\
\hline Daoud Study (1997) & $70 \%$ \\
\hline Ashrafi MR Study (1999) & $30 \%$ \\
\hline Present Study & $30.43 \%$ \\
\hline \multicolumn{2}{|c|}{ Table 5. Comparison among Different Studies regarding Percentage of Children with Breath Holding Spells } \\
having Positive Parental Consanguinity
\end{tabular}

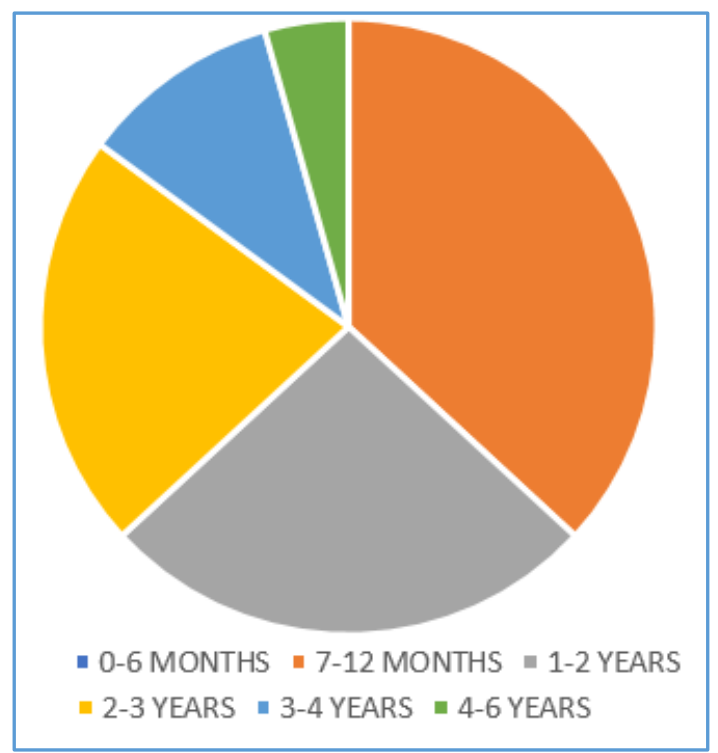

Figure 1. Pie Diagram showing Age Wise distribution of Children with Breath Holding Spells in the Present Study

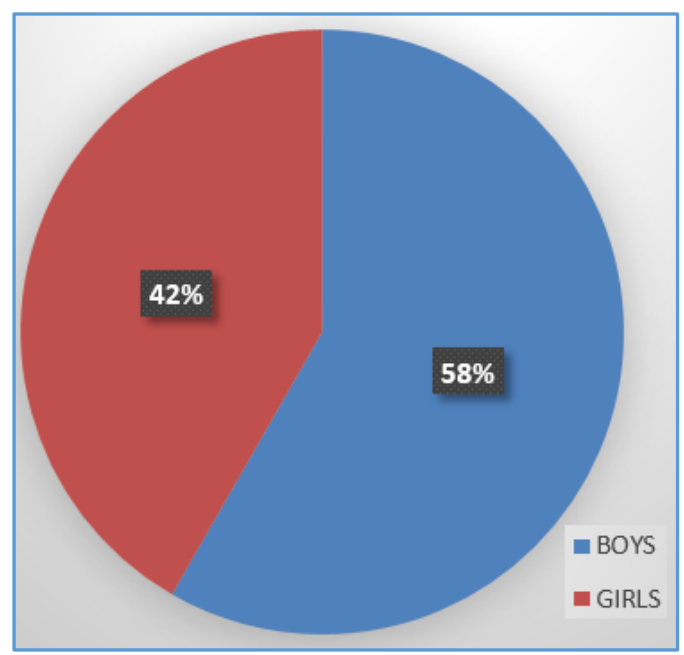

Figure 2. Sex Wise distribution of Breath Holding Spells in the Present Study

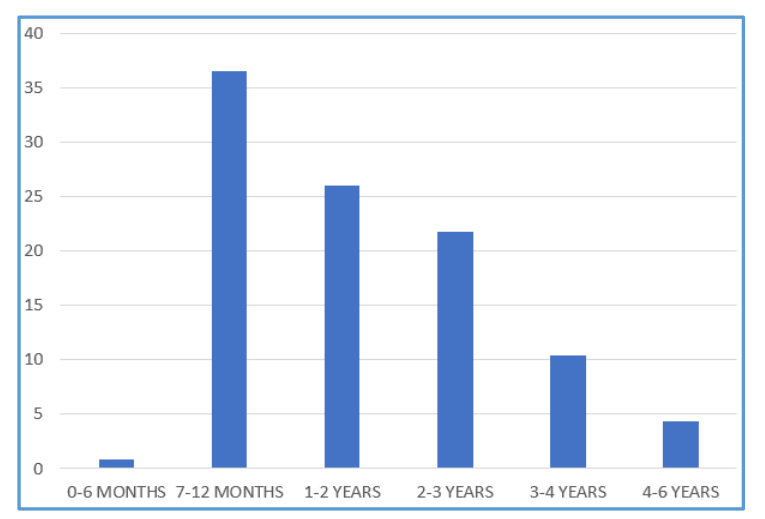

Figure 3. Age Wise distribution of Breath Holding Spells Cases in the Present Study

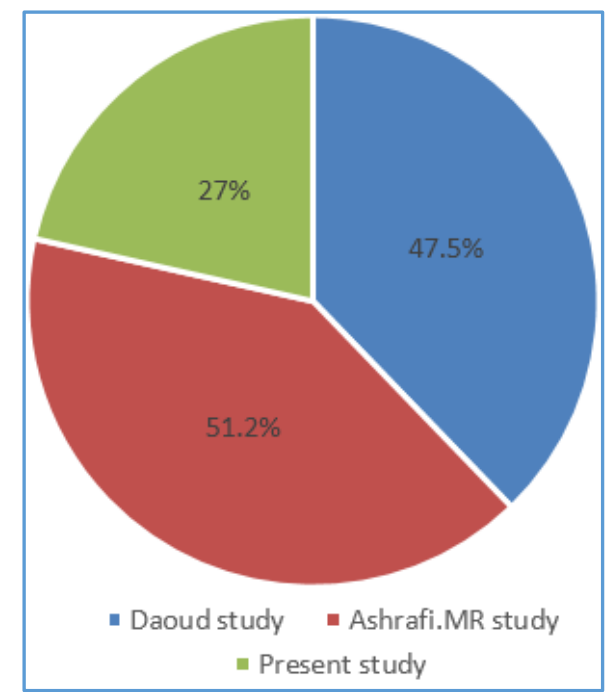

Figure 4. Pie Diagram showing Comparison of Positive Family History of Breath Holding Spells (in \%) among Different Studies

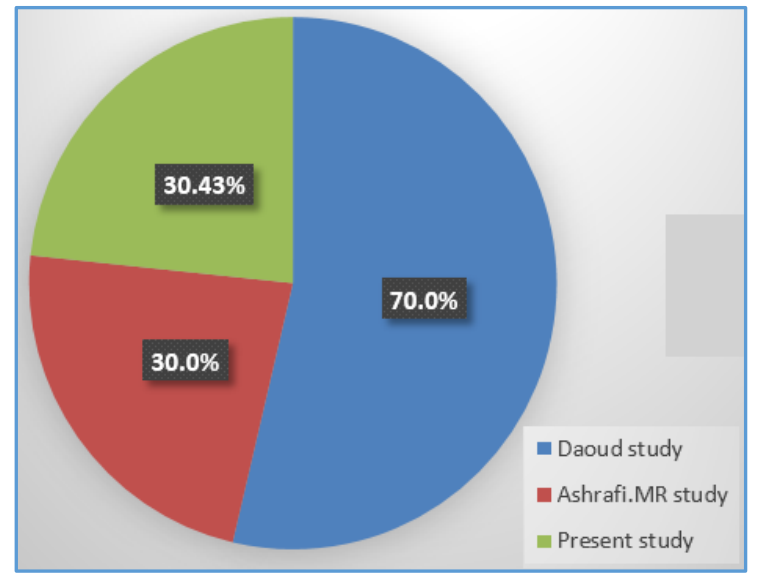

Figure 5. Pie Diagram showing Percentage of Cases with Positive History of Parental Consanguinity in Children with Breath Holding Spells among different Studies

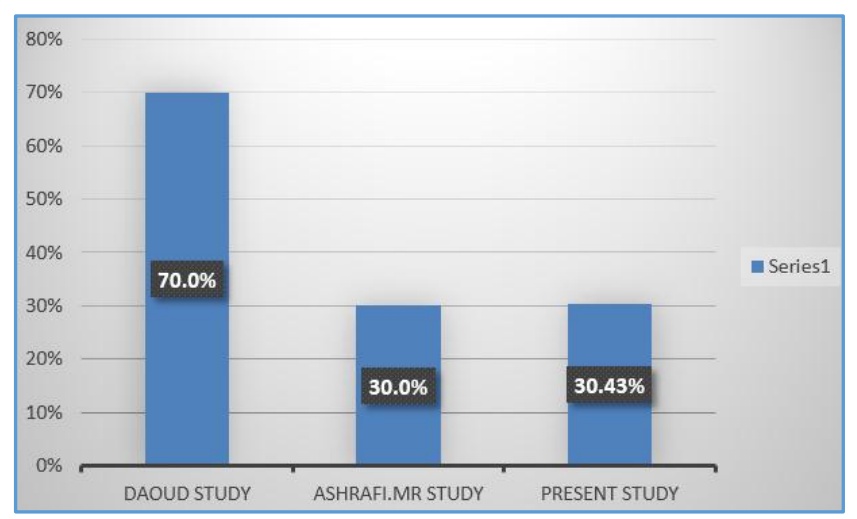

Figure 6. Bar Diagram showing Percentage of Cases with Positive History of Parental Consanguinity in Children with Breath Holding Spells among Different Studies 


\section{DISCUSSION}

Breath holding spells is a common behavioural disorder of early childhood associated with a lot of parental anxiety, besides carrying a potential for misdiagnosis. The earliest reference to Breath holding spells, then referred to as infantile form of temper tantrums or infantile syncope was made by Rillet and Barthezin in 1843, and by Meigsin in 1848. Subsequently, various authors published their clinical viewpoints on its pathophysiology and prognostic significance. Based on the colour change demonstrated by the child during the spell, Breath holding spells were classified as cyanotic, pallid and mixed. Multiple factors like disturbed parent-child relationship, hereditary autonomic instability, self-asphyxiation, decreased cerebral blood flow secondary to increased intrathoracic pressure due to spontaneous Valsalva manoeuvre and altered cerebral mechanism secondary to various stimuli were implicated for cyanotic Breath holding spells. ${ }^{5}$ Breath holding spell occurs most commonly within the first 18 months of age and $90 \%$ or more of breath holders have their initial spell by age 2 years. In approximately half of all children with severe spells, the spells terminate by age 4 years. Virtually, all breath holders cease experiencing episodes by 7 - 8 years of age. A family history of Breath holding spells may be present. ${ }^{6}$ Some investigators found an increased incidence of syncope in later life in patients with a history of Breath holding spells. Aside from this, no lasting sequelae of Breath holding spells are anticipated of children who experience Breath holding spell, $54 \%$ - $62 \%$ are cyanotic, $19 \%-22 \%$ pallid and $19 \%-24 \%$ mixed or unclassifiable. In some children Breath holding spells at their apex occur many times a day. The peak frequency is generally present in the second-year life. Forms of anoxic seizures occurs in early childhood with considerable frequency. Anoxic seizures are dependent on the sudden depression of function of population of neurons due to ischaemia or asphyxia, in contrast to epileptic seizures which is simply the excessive discharge of a population of neurons. Two particularly common form of anoxic seizures in early childhood have been termed Breath holding spells. Breath holding spells have been subdivided as cyanotic or pallid based on the coloration of the child during the event.5,7,8 Despite ample literature regarding these two types of anoxic seizures, parents and practitioners continue to confuse these with epileptic seizures. Indeed, in some children Breath holding spells may be the precipitation of epileptic seizure or status epilepticus enhancing the confusion. ${ }^{9}$ The striking association of anaemia with Breath holding spells was first reported in 1963 by Halowach and Thurston. ${ }^{10}$ It was hypothesised that the low haemoglobin causes rapid cerebral anoxia due to decreased oxygen carrying capacity of blood that in turn leads to the Breath holding spells. It was also thought that the anaemic children being irritable may be more predisposed to Breath holding spells.

A vivid description of typical pallid Breath holding spells was given by Stephenson. ${ }^{11}$ The precipitant for typical Breath holding spells is usually sudden, unexpected, unpleasant stimulus, frequently a mild injury to the head. Crying, if present, is not prominent. Generally, cyanosis is not present. Pallor and diaphoresis are common. The patient may be somnolent or go to sleep following the episode. In children experiencing Breath holding spells, whether pallid or cyanotic the first episode usually occurs by 18 months of age. ${ }^{8}$ Breath holding per se with attendant cyanosis is the characteristic features of cyanotic Breath holding spells. Rouessen describes a cyanotic Breath holding spell which terminates, as frequently these do before syncope is reached. 12 The pathophysiology of cyanotic Breath holding spell is more complicated than that of pallid Breath holding spell. Cyanosis occurs in these patients with surprising rapidity. Cyanotic breath holding involves a diminished pulmonary oxygen reserve. Two infants with cyanotic Breath holding spells studied by Gauk et al $^{13}$ were reported to experience pronounced oxygen desaturation with arterial hypertension and no significant alteration in pulse rate. Anoxic anoxia was deemed to be the mechanism for the loss of consciousness in these patients. A mechanism for cyanotic Breath holding spell was then advanced involving violent crying leading to hypocapnic cerebral ischaemia and respiratory spasm leading to increased intrathoracic pressure as well as apnoea proceeding to hypoxaemia. ${ }^{5}$ The hypocapnia and Valsalva manoeuvre combine to decrease arterial inflow and increase resistance to outflow in the cerebral circulation. It is proposed that interactions among central sympathetic activity, brain stem control of respiration and vasomotor activity, reflexes arising from around and within the respiratory tract and the matching of ventilation to perfusion account for the intrapulmonary shunting and expiratory apnoea occurring in these patients. A recent case control study from Turkey reported maturation delay in myelination of the brainstem as assessed from the interpeak latencies on brainstem auditory evoked potential, as the cause of Breath-holding spells. ${ }^{14}$ Pallid and cyanotic Breath holding spells both are frequent causes of syncope and anoxic seizures in early childhood. Both most generally occur in otherwise healthy children and both spontaneously resolve without sequel. History is the mainstay of diagnosis. ${ }^{9}$ Obtaining an accurate and detailed history of the episodes of concern is critical in the diagnosis of Breath holding spells. Pallid Breath holding spells occur in the context of an injury, frequently an unexpected blow to the head. Cyanotic Breath holding spells occur in the setting of anger and upset. Any losses of consciousness or seizure in early childhood that are provoked by either of these antecedents are primarily suspected to be anoxic in character. Epileptic seizures generally not provoked by anger or injury in the setting of a normal general and neurological examination. Laboratory testing usually adds little information. Difficulty in diagnosis may arise when certain of episodes are not witnessed from their initiation. Another diagnostic difficulty, to be discussed later, occurs when Breath holding spells in turn provoke epileptic seizures. Videotape documentation of typical episode may be considerable value. ${ }^{9}$ Patients with pallid Breath holding spells have frequently been studied with an electroencephalogram, during which ocular compression is performed. Patients with Breath holding spells may follow this EEG evolution without significant bradycardia or asystole. Spontaneously recorded Breath holding spells recapitulated this sequence of EEG alterations.8,9 Prolonged QT syndrome is rare, but potentially malignant cause of anoxic seizure. It is recommended that an ECG (Electrocardiogram) to screen for prolonged QT syndrome be performed. ${ }^{9}$ Anaemia may be a factor contributing to Breath holding spells in some children. Febrile illness may also be a precipitant of Breath holding spell in some children. Breath 
holding spells were observed more frequently in boys than in girls. In our study the ratios were found to be 1.1: 1, 3: 1 , 1.7:1 and 1.3: 1 in Ashrafi et al, ${ }^{15}$ Lombroso et al, ${ }^{5}$ Diamario et $\mathrm{al}^{8}$ and Goraya et $\mathrm{al}^{16}$ studies respectively. In a group of 384 children ( 3 months to 4 years) studied by Livingston, the mean age at onset of Breath holding spell was 12 months. In the present study, the minimum age at the onset of first spell was 6 months and upper age was 66 months. We found the mean age at the onset of Breath holding spells was 20.42 months in our study population $(n=115)$. Bhatia et $\mathrm{al}^{17}$ reported $80 \%$ of their cases experienced Breath holding spells during the first 18 months of age. In Ashrafi et al ${ }^{15}$ study, $76.8 \%$ of cases had their spells begun during their first year of age. But in the present study, about $63.41 \%$ of cases (73 out of 115) had their spells begun during the first 24 months of age. Data from more detailed analyses suggest an autosomal dominant pattern of inheritance in some cases of breath holding spells. $5,8,9,18$ A positive family history of Breath holding spells was found in $27 \%$ of our cases (31 out of 115 ), whereas positive family histories of Breath holding spells were found to be $51.2 \%$ and $47.5 \%$ in Ashrafi et al ${ }^{15}$ and Daoud et al studies respectively. Parental consanguinity was found in $30.43 \%$ of our cases, whereas it was $30 \%$ and $70 \%$ in Daoud et al studies respectively. The most common triggering factors for Breath holding spells in our study found to be anger $(45.2 \%)$ and pain $(41.7 \%)$. This finding was in agreement with previous studies. In our study, the most common type was cyanotic Breath holding spells (66.1\%) which was in agreement with previous study reports. $4,5,8,9,15,17$ Based on number of previous studies, it is now well established that checking for iron deficiency or anaemia is probably worthwhile and also a trial of iron therapy is beneficial in reducing the frequency of Breath holding spells, especially in children with laboratory evidence of anaemia. ${ }^{19}$ Chandra et al study was carried out in Chandigarh with the objective of assessing the haemoglobin levels in children with Breath holding spells and determining the therapeutic role of iron in its management. It was also shown that iron therapy showed a more remarkable therapeutic benefit in controlling the spells in children with evidence of iron deficiency. ${ }^{20}$

In the present study, anaemia was found in $76.52 \%$ (88 out of 115) of cases. After diagnosis of Breath holding spells is established, explanation and reassurance to families is the mainstay of therapy. The occurrence of Breath holding spells per se should not lead to any alteration in the general care of the child. 8 Breath holding spells usually mimic or are confused with seizure disorder and can be a frightening experience for parents. Since the diagnosis is made clinically, it demands a good history of sequence of events. Lack of incontinence and postictal phase helps to make an accurate diagnosis.

Education and reassurance of the parents, usually all that is needed as these episodes are as a rule self-limited and are outgrown within a few years or by school age. However, treatment of co-existing iron deficiency is needed if it is present, as the spells are made worse by iron deficiency anaemia. It is neither feasible nor helpful to avoid circumstances which may provoke Breath holding spells. ${ }^{9}$ If Breath holding spells occur, placing the child in a lateral recumbent position is appropriate until recovery occurs. Cardiopulmonary resuscitation should generally be avoided. In the considerable minority of patients with particularly severe Breath holding spells, treatment with atropine Sulphate or methonitrate has been utilised.21 Transdermal scopolamine ${ }^{22}$ or even pacemaker implantation has also been utilised. ${ }^{23,24}$ Recently, evidence for safe and effective use of piracetam, especially in hyperactive children to control Breath holding spells has emerged, but it still lacks FDA approval.19,25

\section{CONCLUSION}

The result of this study suggests a new data regarding clinical and epidemiological profile of Breath holding spells and is important for identifying interventional strategies and parental counselling and could serve as baseline data for future approaches on this paediatric clinical entity.

\section{REFERENCES}

[1] Colina KF, Abelson HT. Resolution of breath-holding spells with treatment of concomitant anemia. J Pediatr 1995;126(3):395-7.

[2] Tonekaboni SH, Alavi S, Mahvelati F, et al. Effects of oral iron supplement on breath-holding spells in children. Iran J Child Neurol 2006;1(1):33-7.

[3] Bhat MA, Ali W, Mohidin K, et al. Prospective study of severe breath holding spells and role of iron. Indian Journal of Pediatric Neurology 2007;5(1):27-32.

[4] Daoud AS, Batieha A, Al-Sheyyab M, et al. Effectiveness of iron therapy on breath-holding spells. J Pediatr 1997;130(4):547-50.

[5] Lombroso CT, Lerman P. Breathholding spells (cyanotic and pallid infantile syncope). Pediatrics 1967;39(4):563-81.

[6] Silbert PL, Gubbay SS. Familial cyanotic breath-holding spells. J Paediatr Child Health 1992;28(3):254-6.

[7] Laxdal T, Gomez MR, Reiher J. Cyanotic and pallid syncopal attacks in children (breath-holding spells). Dev Med Child Neurol 1969;11(6):755-63.

[8] Dimario FJ. Breath holding spells in childhood. Am J Dis Child 1992;146(1):125-31.

[9] Breningstall GN. Breath-holding spells. Pediatr Neurol 1996;14(2):91-7.

[10] Holowach J, Thurston DL. Breath-holding spells and anemia. N Engl J Med 1963;268:21-3.

[11] Stephenson JB. Reflex anoxic seizures ('while breathholding'): nonepileptic vagal attacks. Arch Dis Child 1978;53(3):193-200.

[12] Peiper A. Cerebral function in infancy and childhood translation of the $3^{\text {rd }}$ German edn. New York: Consultants bureau, 1963:371-4.

[13] Gauk EW, Kidd L, Prichard JS. Mechanism of seizures associated with breath holding spells. N Engl J Med 1963;268:1436-41.

[14] Vurucu S, Karaoglu A, Paksu SM, et al. Breath holding spells may be associated with maturational delay in myelination of brain stem. J Clin Neurophysiol 2014;31(1):99-101.

[15] Ashrafi MR, Shajari H, Salajegheh N, et al. Breath holding spells: an analysis of 43 cases. Iran J Child Neurology 2006:17-20.

[16] Goraya JS, Virdi VS. Persistence of breath holing spells into late childhood. J Child Neurol 2001;16(9):697-8. 


\section{Jemds.com}

[17] Bhatia MS, Singhal PK, Dhar NK, et al. Breath-holding spells: an analysis of 50 cases. Indian Pediatr 1990;27(10):1073-9.

[18] DiMario FJ, Sarfarazi M. Family pedigree analysis of children with severe breath-holding spells. J Pediatr 1997;130(4):647-51.

[19] Singh P, Seth A. Breath holding spells-a tale of 50 years. Indian Paediatri 2015;52(8):695-6.

[20] Chandra RK. Association of breath-holding attacks with anemia and their treatment. Indian Pediatr 1965;2:295-7.

[21] McWilliam RC, Stephenson JB. Atropine treatment of reflex anoxic seizure. Arch Dis Child 1984;59(5): 473-5.

\section{Original Research Article}

[22] Palm L, Blennow G. Transdermal anticholinergic treatment of reflex anoxic seizures. Acta Paediatr Scand 1985;74(5):803-4.

[23] Kelly AM, Porter CJ, McGoon MD, et al. Breath-holding spells associated with significant bradycardia: successful treatment with permanent pacemaker implantation. Pediatrics 2001;108(3):698-702.

[24] Sapire DW, Casta A, Safley W, et al. Vasovagal syncope in children requiring pacemaker implantation. Am Heart J 1983;106(6):1406-11.

[25] Sawires H, Botrous O. Double blind, placebo-controlled trial on the effect of piracetam on breath-holding spells. Eur J Pediatr 2012;171(7):1063-7. 